\title{
Expression of Sindbis Virus 26S cDNA in Spodoptera frugiperda (Sf9) Cells, Using a Baculovirus Expression Vector
}

\author{
CHRISTIAN OKER-BLOM AND MAX D. SUMMERS* \\ Department of Entomology, Texas A\&M University, and Texas Agricultural Experiment Station, \\ College Station, Texas 77843-2475
}

Received 1 September 1988/Accepted 18 November 1988

\begin{abstract}
To study protein processing in an insect Spodoptera frugiperda (fall armyworm; Sf9) cell line, a 26S cDNA encoding the sequence of Sindbis virus structural proteins (capsid protein, of 30 kilodaltons [kDa]; p62 [the precursor of E3 and E2], of $62 \mathrm{kDa}$; a 6-kDa peptide; and the E1 protein, of $56 \mathrm{kDa}$ ) was inserted into the genome of Autographa californica nuclear polyhedrosis virus (AcNPV) adjacent to the polyhedrin promoter. By immunoblot analysis with antisera directed against whole Sindbis virus and the individual structural proteins (capsid, E2, and E1), we have shown that polypeptides similar in size and antigenicity to those synthesized in Sindbis virus-infected BHK cells are expressed in Sf9 cells infected with the recombinant baculovirus Ac373-SV26. By pulse-chase labeling in the presence or absence of tunicamycin, by endo- $\beta$ - $N$-acetylglucosaminidase $H$ (endo-H) treatment of the recombinant glycoproteins, and by $N$-terminal sequence analysis of the E1 envelope glycoprotein, we have further shown that the $26 S$ transcription translation unit of Sindbis virus, although normally encoded by nonnuclear RNA, is expressed and proteolytically cleaved similarly, if not identically, in Sf9 cells as compared with BHK cells when a baculovirus expression vector is used.
\end{abstract}

A baculovirus expression vector, utilizing Autographa californica nuclear polyhedrosis virus (AcNPV) polyhedrin promoter, has been developed for the expression of a variety of procaryotic and eucaryotic genes as either fusion or nonfusion recombinant proteins (reviewed in reference 16). Relatively abundant levels of expression have been achieved from recombinant genes driven by the strong polyhedrin promoter. Recombinant proteins have been shown to be targeted, glycosylated, and secreted similarly to their authentic counterparts. Recombinant protein products compared by antigenicity, immunology, and functional studies xhave also been shown to retain many of their original properties (16). Little is known, however, about proteolytic processing of recombinant polyproteins in Sf9 cells (for a review, see M. D. Summers, in A. L. Notkins and M. B. A. Oldstone, ed., Concepts in Viral Pathogenesis, vol. 3, in press).

Sindbis virus is a small, simple RNA virus that belongs to the Alphavirus genus within the Togaviridae family. The nucleocapsid containing the single-stranded RNA complexed with a basic capsid protein $(C)$ is surrounded by a lipid bilayer containing two integral membrane glycoproteins (E2 and E1) (reviewed in references 3, 8, 26-28, 32, and 33). The translation of these structural proteins is initiated at a single site on a subgenomic 26S RNA. Three cotranslational cleavages have been shown to release the capsid protein $(30$ kilodaltons [kDa]), p62 or pE2 (62 kDa; the precursor of E3 and $\mathrm{E} 2$ proteins), a 6-kDa peptide consisting of 55 amino acid residues, and the $\mathrm{E} 1$ protein $(56 \mathrm{kDa})$. The capsid protein is cleaved, whereas the polyprotein is nascent. This is believed to be due to an autoproteolytic activity that resides in the capsid protein itself. The two subsequent cotranslational proteolytic cleavages (the release of the $6-\mathrm{kDa}$ peptide that cleaves p62 and E1 from one another) are very probably due to the activity of a host cell protease. Signal peptidase has

\footnotetext{
* Corresponding author.
}

been suggested to be responsible for these two proteolytic events. The conversion of p62 to E2 occurs late in transGolgi. This posttranslational cleavage has been suggested to be host specific.

In this study, we have used the cloned cDNA for Sindbis virus 26S RNA, encoding the structural proteins of the virus, to study protein processing of the Sindbis virus polyprotein in Spodoptera frugiperda (Sf9) cells. The transcription of the $26 \mathrm{~S}$ mRNA, which normally occurs in the cytoplasm of Sindbis virus-infected vertebrate cells, takes place in the nucleus of baculovirus-infected invertebrate cells. We have shown that $\mathrm{Sf} 9$ cells infected with a recombinant baculovirus synthesize polypeptides that are similar to those synthesized in Sindbis virus-infected BHK cells. The results thus show that Sindbis virus structural proteins that normally are encoded by nonnuclear RNAs are expressed and proteolytically processed similarly, if not identically, in Sf9 cells and BHK cells.

\section{MATERIALS AND METHODS}

Cells and virus. Sf9 cells were propagated either as a suspension or as monolayer cultures in TNMFH medium supplemented with $10 \%$ fetal calf serum (Hazelton/K.C. Biologicals, Lenexa, Kans.) at $28^{\circ} \mathrm{C}$ (34). A recombinant baculovirus containing the entire $26 \mathrm{~S}$ cDNA coding sequence of Sindbis virus driven by a polyhedrin promoter was produced by cotransfection of plasmid pAc373-SV26 (Fig. 1) with wild-type AcNPV (strain E2) DNA into Sf9 cells. The recombinant baculovirus (Ac373-SV26) was isolated, plaque purified, and propagated as previously described (34).

BHK cells and Sindbis virus were obtained from Sondra Schlesinger, Washington University School of Medicine, St. Louis, Mo. Cells were grown as monolayer cultures in Eagle minimal essential medium supplemented with $10 \%$ fetal calf serum (GIBCO Laboratories, Grand Island, N.Y.).

Recombinant plasmid constructions. Standard recombinant DNA techniques were used for construction of recombinant 

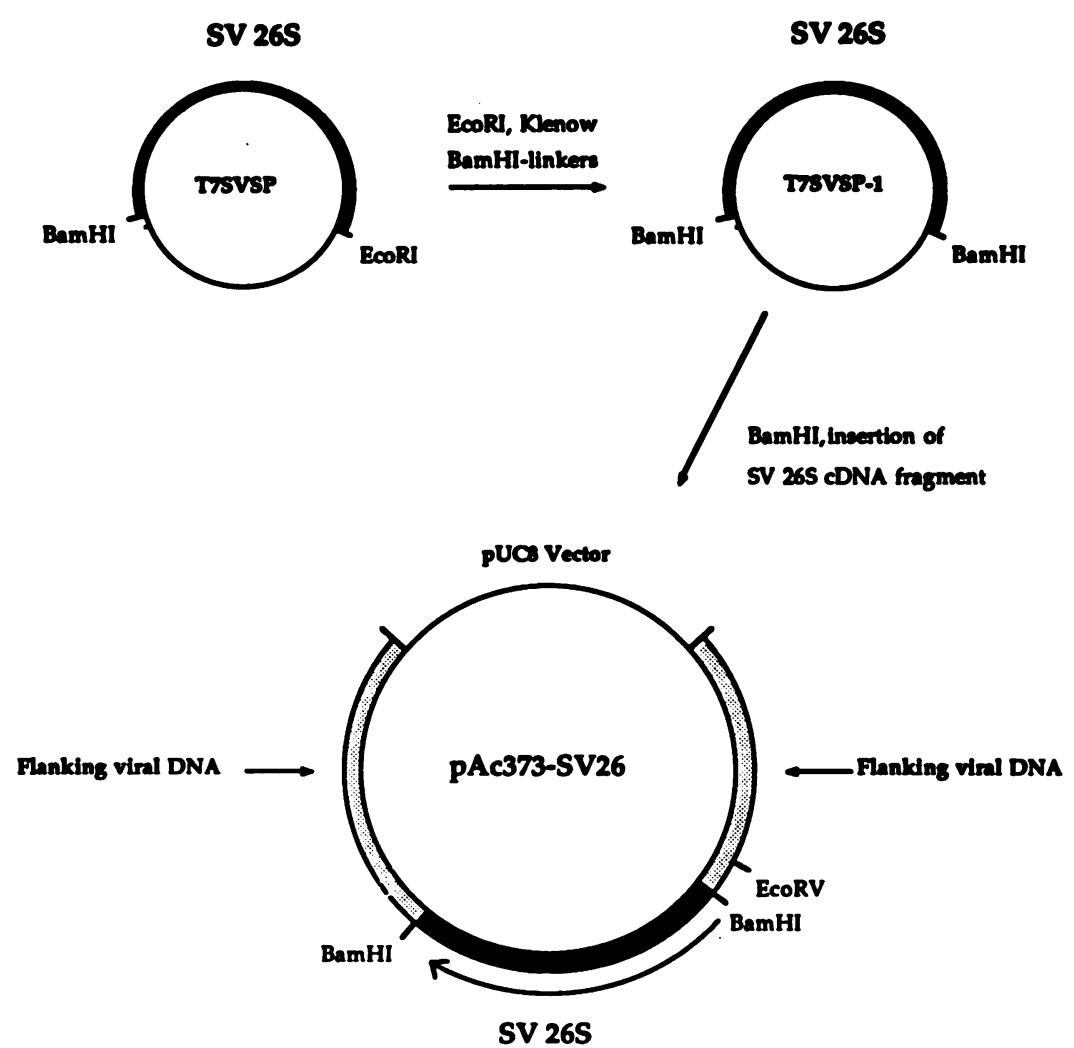

FIG. 1. Schematic presentation of recombinant procedures used to generate plasmid .pAc373-SV26. T7SVSP was digested with EcoRI. The protruding ends were made blunt with T4 DNA polymerase, and BamHI linkers were added. The resulting Bam HI fragment was reinserted to generate T7SVSP-1. After propagation, this fragment was inserted downstream of the polyhedrin promoter in plasmid pAc373 (34) to produce the plasmid pAc373-SV26. In pAc373-SV26, the 26 S coding region of Sindbis virus is driven by the baculovirus polyhedrin promoter but the original Sindbis virus 26S AUG is provided for translational start.

plasmids (17). The entire structural protein region of Sindbis virus (26S) including the poly $(A)$ tail inserted into the pGEM-4 vector (Promega Biotec, Madison, Wis.) was used (Fig. 1). This plasmid was kindly provided by James Strauss and Chang Hahn, California Institute of Technology, Pasadena, Calif. The plasmid T7SVSP was digested with EcoRI and filled in with Escherichia coli DNA polymerase (Klenow fragment). Phosphorylated BamHI linkers (New England BioLabs, Inc. Beverly, Mass.) were added to the ends with T4 DNA ligase. After digestion with BamHI, the fragment was religated to the plasmid to generate T7SVSP-1. The plasmid pAc373 was digested with BamHI, dephosphorylated with calf thymus alkaline phosphatase, and used for insertion of the gel-purified BamHI fragment from T7SVSP1. A recombinant plasmid containing the insert in the correct transcriptional orientation was designated pAc373-SV26. This transfer vector was used to generate recombinant baculovirus through transfection and homologous recombination as described above.

Immunoblot analysis. The immunoblotting procedure was mainly as previously described (38). Sf9 cells $\left(1.2 \times 10^{7}\right.$ cells per tube) in 15-ml tubes (Corning Glass Works, Corning, N.Y.) were pelleted by low-speed centrifugation $(300 \times g$ for 2 min), infected with approximately 20 PFU of Ac373-SV26 per cell, and incubated at $28^{\circ} \mathrm{C}$ with gentle agitation. At 24 , 48 , and $72 \mathrm{~h}$ postinfection (p.i.), respectively, aliquots of $2 \times$ $10^{6}$ cells were removed. Cells were pelleted by low-speed centrifugation as described above and disrupted with $1 \times$ Laemmli disruption buffer (15). An equal amount of Sf9 cells infected with wild-type baculovirus (AcNPV) and mockinfected Sf9 cells served as controls. In addition, BHK cells in six-well plates (see below) infected with approximately 50 PFU of Sindbis virus and mock-infected BHK cells were treated as above at $8 \mathrm{~h}$ p.i. and used as controls. Sucrose gradient-purified virion envelope glycoproteins E1 and E2 (provided by Hans Nitschko, Washington University School of Medicine, St. Louis, Mo.) were compared as quantitative controls ( $1 \mu \mathrm{g}$ of each protein). Samples were boiled for 2 $\mathrm{min}$, and aliquots corresponding to $5 \times 10^{4}$ cells were electrophoresed on sodium dodecyl sulfate SDS $10 \%$ polyacrylamide gels as described below. After separation by SDS-gel electrophoresis, the proteins were transferred to Zeta-Probe Blotting Membranes (Bio-Rad Laboratories, Richmond, Calif.) and allowed to react with antibodies directed against whole Sindbis virus and the individual structural proteins capsid, E2, and E1 (at dilutions of 1:500). The proteins were visualized by using alkaline phosphataseconjugated anti-rabbit immunoglobulin G (Promega Biotec). The antibodies against whole virus were provided by Dennis Brown, University of Texas, Austin, and the antibodies against the individual proteins were provided by James Strauss, California Institute of Technology.

Metabolic radioactive labeling and fractionation of cellular and cytoplasmic extracts. Sf9 cells in $15-\mathrm{ml}$ tubes were infected with the recombinant virus (Ac373-SV26) as described above. At $23 \mathrm{~h}$ p.i., cells were pelleted as above and the medium was replaced with Grace medium lacking methionine (34). After $1 \mathrm{~h}$ of starvation, the cells were concen- 
trated as described above and suspended in $1 \mathrm{ml}$ of Grace medium lacking methionine. For labeling, $100 \mu \mathrm{Ci}$ of $\left[{ }^{35} \mathrm{~S}\right]-$ Translabel (ICN Radiochemicals, Irvine, Calif.) hydrolysate containing approximately $80 \%\left[{ }^{35} \mathrm{~S}\right]$ methionine and $20 \%$ $\left[{ }^{35} \mathrm{~S}\right]$ cysteine per $\mathrm{ml}$ was added. Labeling was carried out for $15 \mathrm{~min}$, and the cells were concentrated as described above and then suspended in $6 \mathrm{ml}$ of medium containing a 20-fold excess of the normal amount of unlabeled methionine and $100 \mu \mathrm{g}$ of cycloheximide per ml. Aliquots $\left(1 \mathrm{ml} ; 1.0 \times 10^{6}\right.$ cells) were taken 0 to $6 \mathrm{~h}$ postlabeling depending on the experiment. Media and cells were separated by low-speed centrifugation. Cell extracts were prepared by disrupting the cells with ice-cold RIPA buffer $(50 \mathrm{mM}$ Tris hydrochloride [pH 8.0], $100 \mathrm{mM} \mathrm{NaCl}, 1 \%$ Nonidet $\mathrm{P}-40,1 \%$ sodium deoxycholate, $0.1 \%$ SDS). Lysates were kept on ice for 10 min and then clarified at $12,000 \times g$ for $10 \mathrm{~min}$. Supernatant media were further pelleted for $15 \mathrm{~min}$, Nonidet P-40 was added to a final concentration of $1 \%$, and the media were kept on ice, clarified, and used for immunoprecipitation as described above.

Metabolic labeling in the absence or presence of tunicamycin $(2 \mu \mathrm{g} / \mathrm{ml}$ added 2 to $4 \mathrm{~h}$ prior to labeling; CalbiochemBehring, La Jolla, Calif.) was carried out at $24 \mathrm{~h}$ p.i. for $1 \mathrm{~h}$ with $50 \mu \mathrm{Ci}$ of $\left[{ }^{35} \mathrm{~S}\right]$-Translabel per $\mathrm{ml}$ of medium. Cell extracts used for immunoprecipitation were prepared as described above.

BHK cells in six-well plates (Corning) were infected with approximately 50 PFU of Sindbis virus (obtained from Sondra Schlesinger) per cell. After $1 \mathrm{~h}$ of adsorption at $37^{\circ} \mathrm{C}$, cells were washed once with Eagle minimal essential medium containing $10 \%$ fetal calf serum, and $2 \mathrm{ml}$ of the same medium was added. At $2 \mathrm{~h}$ p.i., medium was replaced with medium lacking methionine, and cells were starved for $1 \mathrm{~h}$. Pulse-labeling was carried out for $15 \mathrm{~min}$ at $28^{\circ} \mathrm{C}$ with 100 $\mu \mathrm{Ci}$ of $\left.{ }^{35} \mathrm{~S}\right]$-Translabel per $\mathrm{ml}$ and chased for $0,15,30,60$, and 120 min with medium containing a 20 -fold excess of methionine and $100 \mu \mathrm{g}$ of cycloheximide per ml. Cytoplasmic extracts were made by using NET buffer (1\% Nonidet P-40, 0.4 M NaCl, 0.05 M Tris [pH 8.0], 0.005 M EDTA). Lysates were kept on ice and pelleted as described above, and supernatant fluids were used for immunoprecipitation. Metabolic labeling in the absence and presence of tunicamycin $(2 \mu \mathrm{g} / \mathrm{ml})$ was carried out for $1 \mathrm{~h}$ at $3 \mathrm{~h}$ p.i. at $37^{\circ} \mathrm{C}$. Cytoplasmic extracts to be used for immunoprecipitation were prepared as described above and previously (22).

Immunoprecipitation. For immunoprecipitation, cell or cytoplasmic extracts were diluted into $1 \mathrm{ml}$ of RIPA and NET buffer, respectively, and 1 to $5 \mu l$ of antiserum (antiSV, anti-E1, anti-E2, or anti-C) and protein A-Sepharose CL-4B (1 to $2 \mathrm{mg}$; Pharmacia, Uppsala, Sweden) were added. The mixtures were incubated on ice over night. After incubation, immunoprecipitates were concentrated, washed, and analyzed as previously described (22). Preparative immunoprecipitation for purification of individual proteins for amino-terminal sequence analysis was done with $25 \mu \mathrm{l}$ of antiserum directed against whole Sindbis virus.

Treatment with endo-H. Labeling of Ac373-SV26-infected Sf9 cells and Sindbis virus-infected BHK cells was as described above. Cell and cytoplasmic extracts were immunoprecipitated by using antibodies against whole virus, as described above. After being washed, the immunoprecipitates were boiled for $2 \mathrm{~min}$ in $0.5 \%$ SDS-0.1 M $\beta$-mercaptoethanol and then diluted threefold with $50 \mathrm{mM}$ sodium phosphate buffer ( $\mathrm{pH}$ 5.7). Samples were incubated in the presence or absence of endo-H $(25 \mathrm{mU}$ of endo- $\beta-N$-acetylglucosaminidase $\mathrm{H}$ per $\mathrm{ml}$; Genzyme, Boston, Mass.) at $37^{\circ} \mathrm{C}$ for $20 \mathrm{~h}$ and separated by SDS-polyacrylamide gel electrophoresis.

Preparation of proteins for amino-terminal sequence analysis. Recombinant Sindbis virus structural proteins from $\mathrm{Sf} 9$ cells, unlabeled or labeled with $\left[{ }^{35} \mathrm{~S}\right]$-Translabel, were immunoprecipitated with antibodies directed against whole virus. After immunoprecipitation, the sample was washed three times with RIPA buffer and once with water. The immune complexes were separated by boiling in the presence of $2 \%$ SDS for $2 \mathrm{~min}$. The sample was further diluted 20 -fold with water and then filtered at $12,000 \times g$ for $5 \mathrm{~min}$ in an Ultrafilter-MC (microcentrifuge filters allowing only molecules smaller than $100 \mathrm{kDa}$ to pass; Millipore Corp., Bedford, Mass.). The filtrates were dried in a SpeedVac Concentrator (Savant Instruments, Farmingdale, N.Y.), suspended in Laemmli disruption buffer lacking SDS, and separated by preparative SDS-polyacrylamide gel electrophoresis as described above and previously (15). After electrophoresis, the proteins were electrophoretically transferred to an Immobilon-P Transmembrane (Millipore) by using a horizontal transfer unit, Polyblot (American Bionetics, Hayward, Calif.), and the transfer procedure recommended by the manufacturer. The Immobilon-P Transmembrane was stained with Coomassie blue, air dried, and prepared for autoradiography. The protein bands were cut out and subjected to amino-terminal sequence analysis as described below.

Amino-terminal sequence analysis. The sequence analysis was done by routine procedures as described elsewhere (13). The protein to be sequenced was transferred to an Immobilon-P Transmembrane and identified as described above. A strip of the membrane ( 2 by $4 \mathrm{~mm}$ ) containing the protein was cut out and covered with a trifluoroacetic acid-treated glass fiber filter. A standard 03RPTH sequencing program was run on the ABI 470A sequencer (Applied Biosystems, Foster City, Calif.), and the resulting phenylthiohydantoinamino acids were analyzed on the on-line $120 \mathrm{~A}$ analyzer (Applied Biosystems).

SDS-polyacrylamide gel electrophoresis. Electrophoresis on vertical slab gels in the presence of SDS was done by the method of Laemmli (15). The acrylamide concentrations in the stacking and the separating gels were 3 and $10 \%$ respectively. Samples were denatured and reduced with $4 \%$ SDS and $10 \% \beta$-mercaptoethanol in the disruption buffer and boiled for $2 \mathrm{~min}$. After electrophoresis, gels were vacuum dried and prepared for autoradiography. High-range ${ }^{14} \mathrm{C}$ labeled molecular weight markers from Bethesda Research Laboratories, Inc., Gaithersburg, Md., were used as standards.

\section{RESULTS}

Identification of Sindbis virus-specific structural proteins synthesized in Sf9 cells. Synthesis of Sindbis virus-specific structural proteins in $\mathrm{Sf} 9$ cells infected with the recombinant baculovirus Ac373-SV26 (Fig. 1) was studied at 24, 48, and $72 \mathrm{~h}$ p.i. by immunoblot analysis. Proteins were separated on SDS-polyacrylamide slab gels and transferred to blotting membranes. Sindbis virus-specific proteins were identified by using antibodies directed against whole virus and the individual structural proteins $\mathrm{C}(30 \mathrm{kDa}), \mathrm{E} 2(51 \mathrm{kDa})$, and $\mathrm{E} 1(56 \mathrm{kDa})$. $\mathrm{Sf} 9$ cells infected with wild-type baculovirus, AcNPV (strain E2), mock-infected Sf9 cells, BHK cells infected with Sindbis virus, mock-infected BHK cells, and sucrose gradient-purified virion envelope glycoproteins served as controls. When antibodies directed against whole 


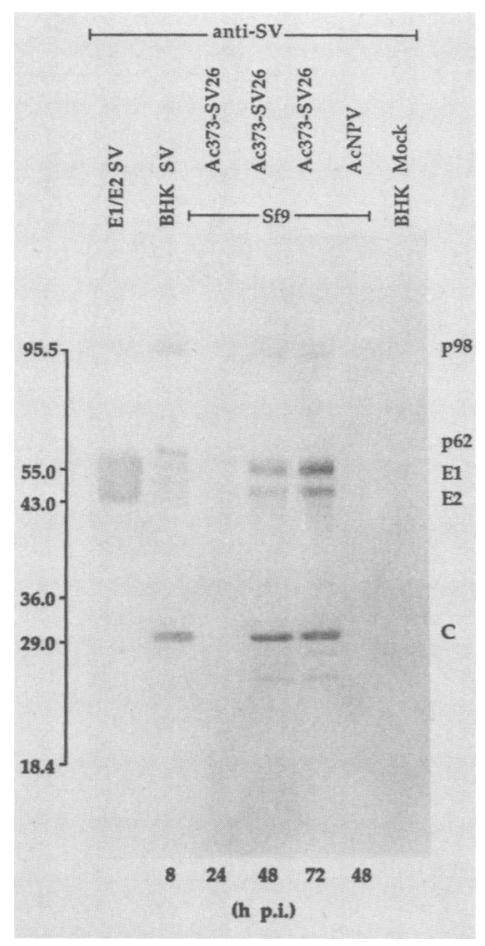

FIG. 2. Immunoblot analysis of Sindbis virus structural proteins synthesized in Sf9 cells by using a recombinant baculovirus (Ac373SV26) containing the 26S cDNA of Sindbis virus (see Materials and Methods). Cell extracts were prepared at 24, 48, and $72 \mathrm{~h} \mathrm{p.i.,} \mathrm{and}$ the proteins were separated by using an SDS-10\% polyacrylamide gel and then electrophoretically transferred to a nitrocellulose membrane. Mature E1 and E2 isolated from whole Sindbis virus (1 $\mu \mathrm{g}$ each) and Sindbis virus-infected BHK cells at $8 \mathrm{~h}$ p.i. were used as controls. Sf9 cells infected with wild-type AcNPV and mockinfected BHK cells are shown on the right. The Sindbis virus proteins were identified by using antiserum directed against purified whole virus (anti-SV). The positions of the molecular weight markers (in thousands) are shown on the left.

Sindbis virus (anti-SV) were used (Fig. 2), a protein comigrating with the capsid protein $(C)$ was resolved from $\mathrm{Sf} 9$ cells. In addition, the $98-\mathrm{kDa}$ polyprotein representing the nonglycosylated precursor of the p62, 6-kDa, and E1 proteins (p98) comigrated from Sf9 cells as compared with the corresponding form identified from Sindbis virus-infected BHK cells. Furthermore, proteins migrating similarly to the processed forms of p98, i.e., p62, E1, and E2, could be identified from $\mathrm{Sf} 9$ cells infected with the recombinant baculovirus. The specificity of the proteins identified with antibodies directed against whole Sindbis virus (anti-SV) was further confirmed by using antibodies directed against the individual viral structural proteins, anti-C, anti-E1, and anti-E2 (Fig. 3). When anti-C antibodies were used, a protein comigrating with the capsid protein from Sindbis virusinfected BHK cells was identified in infected Sf9 cells. The p98 polyprotein was identified by using both anti-E1 and anti-E2. Furthermore, the anti-E1 antibodies recognized a protein migrating slightly faster than the authentic E1 glycoprotein, and the anti-E2 antibodies reacted with two proteins corresponding to the p62 and the processed $\mathrm{E} 2$ proteins. The mobility of the two latter proteins was also slightly higher than that of their authentic counterparts. Both E1 and E2 from purified virions reacted with their specific antisera.
Extracts from BHK cells and Sf9 cells infected with AcNPV did not react with any of the antisera used.

The results indicate that Sindbis virus-specific structural proteins are synthesized in Sf9 cells and that the processing of the polyprotein is similar to that observed in BHK cells. The slightly higher mobility of the recombinant glycoproteins is very probably due to differences in glycosylation, as will be discussed below.

Processing of the Sindbis virus polyprotein in Sf9 cells. To study the processing of the recombinant proteins synthesized in Sf9 cells infected with Ac373-SV26, cells were pulse-labeled with [ ${ }^{35} \mathrm{~S}$ ]-Translabel at $24 \mathrm{~h}$ p.i. for $15 \mathrm{~min}$ and chased for 0 to $5 \mathrm{~h}$ with excess unlabeled methionine (Fig. 4). Cells and media were separated at the different time points postlabeling, and extracts were prepared and immunoprecipitated with antibodies directed against whole Sindbis virus (anti-SV). After no chase, bands corresponding to the p62, $\mathrm{E} 1$, and capsid proteins were immunoprecipitated from the cell extracts. When cells were chased for 1 to $5 \mathrm{~h}$, an additional band, very probably representing the $\mathrm{E} 2$ protein, migrating somewhat faster than the E1 protein, was identified. After a 1-h chase, the capsid protein was barely seen and was not detectable after a 2- to 5-h chase. The three glycoproteins p62, E1, and E2 could still be detected after a 5 -h chase. None of the proteins could be resolved from the supernatant medium at any time point postlabeling. Cell extracts made from Sf9 cells infected with wild-type baculovirus (AcNPV) did not react with the antibodies used.

A comparison of the kinetics of processing in BHK and Sf 9 cells was made by pulse-chase labeling at $28^{\circ} \mathrm{C}$. Infected cells were pulse labeled with $\left[{ }^{35} \mathrm{~S}\right]$-Translabel for $15 \mathrm{~min}$ at 3 and $24 \mathrm{~h}$ p.i. and subjected to 0 - to 120 -min chase periods with excess unlabeled methionine (Fig. 5A and B). At the lower temperature used, processing of p62 to E1 in BHK cells occurred between 30 and $60 \mathrm{~min}$ (Fig. 5A). The kinetics of processing of the p62 polyprotein were thus observed to be similar to those in Sf9 cells (Fig. 4 and Fig. 5B). The p62 protein could, however, still be detected at the end of the chase, suggesting incomplete or very slow cleavage of this protein. The capsid protein, which remained in the BHK system during the entire chase, was barely detectable after a 1- to 2-h chase in the Sf9 cells. This may be due at least partly to degradation, in agreement with the data obtained from the immunoblot analysis (see Discussion).

Effect of tunicamycin and endo-H on the recombinant proteins. Tunicamycin inhibits asparagine-linked glycosylation of proteins $(35,37)$. To study the effect of the drug, Sf9 cells infected with Ac373-SV26 were pretreated for $4 \mathrm{~h}$ with tunicamycin and then pulse-labeled at $24 \mathrm{~h}$ p.i. for $1 \mathrm{~h}$ with $\left[{ }^{35} \mathrm{~S}\right]$-Translabel in the presence of the drug. Cell extracts were prepared, and Sindbis virus-specific proteins were immunoprecipitated by using antiserum to whole virus. BHK cells that were infected with Sindbis virus and labeled in the presence of tunicamycin at $3 \mathrm{~h}$ p.i. for $1 \mathrm{~h}$ after a 2-h pretreatment with the drug served as a control, together with infected $\mathrm{Sf} 9$ and $\mathrm{BHK}$ cells labeled in the absence of the drug (Fig. 6B).

Three major proteins corresponding to the nonglycosylated forms of p62 and E1 and to the capsid protein were immunoprecipitated from BHK cells treated with tunicamycin (Fig. 6B). It has been previously shown that cleavage of p62 to E3 and E2 does not occur in the presence of the drug $(18,25)$. The E1 protein from Sf9 cells comigrated with that from BHK cells. The p62 protein from Sf9 cells migrated slightly faster than that from BHK cells. The p62 from Sf9 cells was also not cleaved to form the E2 protein in the 


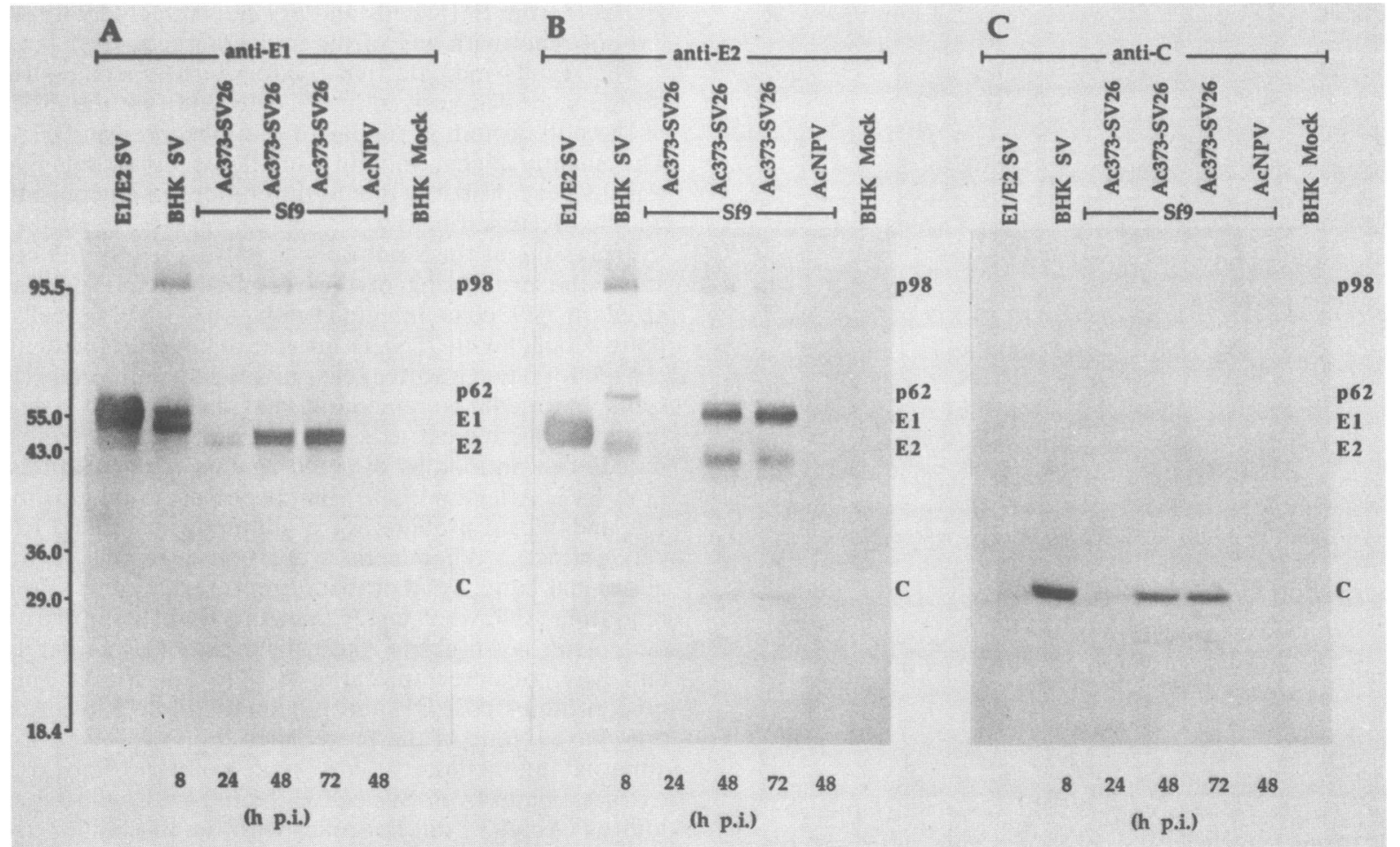

FIG. 3. Immunoblot analysis of recombinant Sindbis virus structural proteins synthesized in Sf9 cells at 24 , 48 , and 72 h p.i. by using antibodies directed against the individual structural proteins anti-E1 (A), anti-E2 (B), and anti-C (C). Proteins were extracted, separated, and electrophoretically transferred to a nitrocellulose membrane as described in the legend to Fig. 2 (see also Materials and Methods). Purified envelope glycoproteins (E1/E2 SV), Sindbis virus-infected BHK cells (BHK SV), wild-type baculovirus-infected Sf9 cells (AcNPV), and mock-infected BHK cells (BHK Mock) served as controls. The positions of the molecular weight markers (in thousands) are shown on the left.

presence of the drug. The capsid protein, which is not glycosylated, was unaffected by the drug.

To further compare the recombinant proteins with the corresponding authentic Sindbis virus proteins, infected Sf9 cells were pulse-labeled for $15 \mathrm{~min}$ with $\left[{ }^{35} \mathrm{~S}\right]$-Translabel at $24 \mathrm{~h}$ p.i.; no chase followed. Under these conditions the p62 protein is not yet processed to form the E2 protein. Cell extracts were prepared and immunoprecipitated by using antibodies directed against whole Sindbis virus. The immune-complexes were treated with endo- $\mathrm{H}$, an enzyme that is known to remove $\mathrm{N}$-linked high-mannose sugar residues (36), separated on SDS-polyacrylamide gels, and prepared for autoradiography. Sindbis virus-infected BHK cells labeled at $28^{\circ} \mathrm{C}$ for $15 \mathrm{~min}$ without chase and untreated recombinant and authentic proteins served as a controls (Fig. 6A). The p62 and E1 proteins from the two systems migrated very similarly after treatment with endo- $\mathrm{H}$, suggesting that p62 and E1 are accurately cleaved from the polyprotein in Sf9 cells.

To further elucidate the processing of the glycoproteins in Sf 9 cells, labeling was carried out as described above, but the cells were chased for 0 to $2 \mathrm{~h}$ and antibodies directed against E1 and E2 (anti-E1 and anti-E2) were used (Fig. 7). The E1 protein (Fig. 7A) showed sensitivity to endo-H even after a 2-h chase. A similar observation was made with the p62 and the E2 proteins, the latter of which was detected after a 30 -min chase. Both proteins were sensitive to the enzyme throughout the chase (Fig. 7B). These results further indicate that the envelope proteins are glycosylated and sensitive to endo- $\mathrm{H}$, suggesting that complex glycosylation does not occur in Sf9 cells. This is in agreement with earlier studies on glycosylation in mosquito cells (12).

$\mathbf{N}$-terminal sequence analysis of the $\mathbf{E} 1$ protein. To confirm the correct cleavage site for recombinant E1 in Sf9 cells, the protein was preparatively isolated and purified as described in Materials and Methods and the amino-terminal sequence was determined by automated Edman degradation. Ten amino acid residues were analyzed; the sequence was TyrGlu-X-Ala-Thr-Thr-Val-Pro-Asn-Val. This result is in complete agreement with that for the authentic Sindbis virus E1 envelope protein (31).

\section{DISCUSSION}

The replication strategy of Sindbis virus in vertebrate cells has been very comprehensively studied $(3,8,26-28,32,33)$. Correct processing of this polyprotein can occur in the absence of viral genomic RNA, suggesting that the nonstructural proteins of the virus are not involved or necessary for the processing of the structural proteins $(14,23)$. Thus, expression of the subgenomic mRNA of Sindbis virus was considered a good model with which to study protein processing in this insect cell line with the baculovirus as a vector.

To study protein processing in Sf9 cells we constructed a recombinant baculovirus which contains the entire cDNA copy of Sindbis virus subgenomic 26S RNA inserted adjacent to the polyhedrin promoter. The cDNA insert is expressed, translated, and processed to Sindbis virus capsid protein $(C)$ and envelope glycoproteins E1 and E2. In 


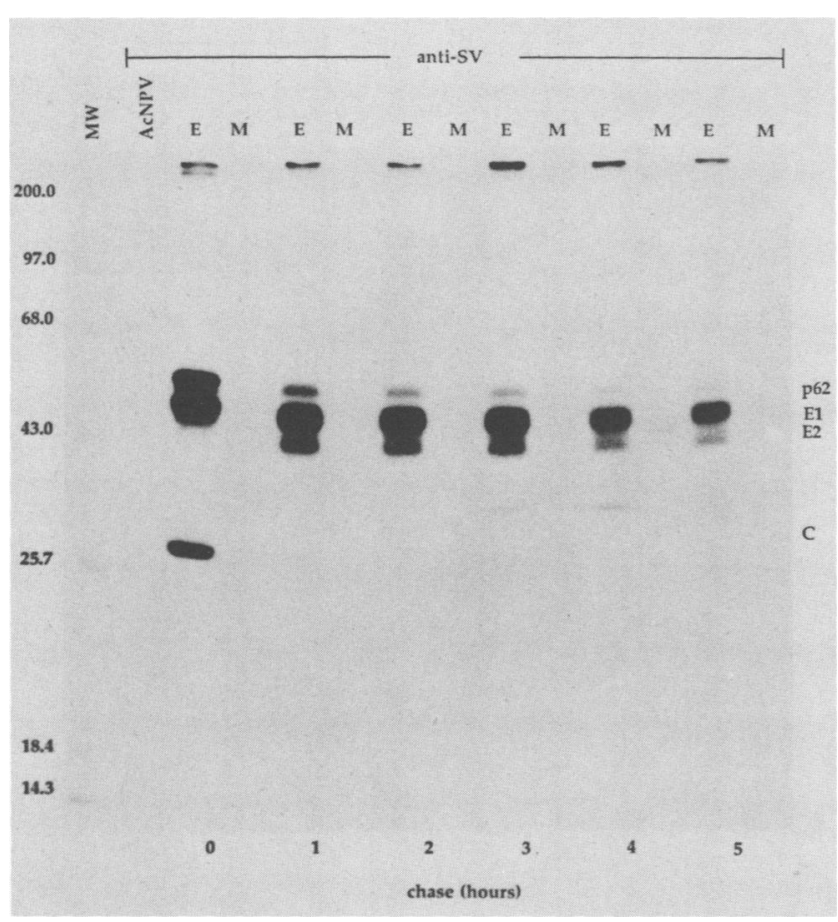

FIG. 4. SDS-gel analysis of the kinetics of Sindbis virus proteins expressed in baculovirus-infected Sf9 cells. Ac373-SV26-infected Sf9 cells were pulse-labeled with $\left[{ }^{35} \mathrm{~S}\right]$-Translabel at $24 \mathrm{~h}$ p.i. for 15 min and then subjected to 0 - to 5 -h chase periods as indicated in the figure. Cell extracts (E) and media (M) were used for immunoprecipitation by using antibodies directed to whole Sindbis virus (anti-SV) as described in the text. Wild-type baculovirus-infected Sf9 cells served as a control (AcNPV). Molecular weight markers (in thousands) are shown on the left.

addition, the precursor forms of the envelope proteins (p98 and $\mathrm{p} 62$ or pE2) were resolved. We have shown that the nonglycosylated forms of the envelope proteins are similar in size to the authentic proteins produced in vertebrate cells and that the $\mathrm{N}$ terminus of the $\mathrm{E} 1$ protein is identical to authentic E1. The results presented here thus indicate that the Sindbis virus polyprotein is proteolytically cleaved similarly, if not identically, in Sf9 cells and BHK cells and that the differences in migration of the glycosylated forms of the envelope proteins very probably are due to differences in glycosylation between the vertebrate and the invertebrate systems (12).

Several proteolytic cleavages are involved in the processing of Alphavirus structural proteins. The capsid protein (C) is believed to be cleaved from the nascent polyprotein by an autoproteolytic activity that resides in the capsid protein (1, $2,4-6,9-11,21,29,30,32)$. Since the capsid protein from Sf9 cells comigrated with that from BHK cells, it is most probably also active in $\mathrm{Sf} 9$ cells, and a correct cleavage of the protein is thus expected. This observation is further supported by the fact that the nonglycosylated $\mathrm{p} 98$ protein (the precursor polyprotein to the $\mathrm{p} 62,6-\mathrm{kDa}$, and $\mathrm{E} 1$ proteins) comigrated in the two systems. In pulse-chase experiments the intensity of the radiolabeled capsid protein declined in Sf9 cells and was no longer detectable after a 1- or 2-h chase. In contrast, the amount of capsid protein detected by immunoblot analysis at 48 and $72 \mathrm{~h}$ p.i. very much resembled that observed in BHK cells. Since no capsid protein was detectable in the culture medium, it is possible

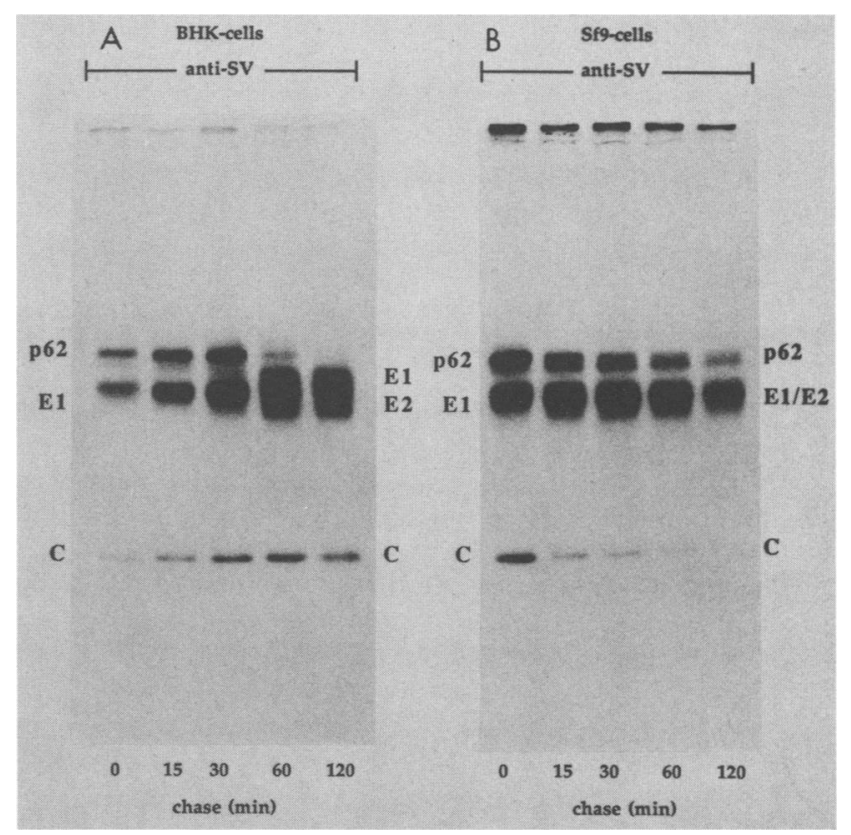

FIG. 5. Comparison of the kinetics of Sindbis virus structural proteins synthesized in $\mathrm{BHK}$ cells at $28^{\circ} \mathrm{C}(\mathrm{A})$ and the respective recombinant proteins synthesized in Sf9 cells (B). Infected BHK and Sf 9 cells were pulse-labeled with $\left[{ }^{35} \mathrm{~S}\right]$-Translabel for $15 \mathrm{~min}$ at 3 and $24 \mathrm{~h}$ p.i., respectively. Cells were chased for $0,15,30,60,120$, and $240 \mathrm{~min}$ as indicated by using excess unlabeled methionine. Cytoplasmic and cell extracts were prepared as described in Materials and Methods, and proteins were immunoprecipitated by using antibodies directed against purified whole Sindbis virus (anti-SV). Proteins were separated on SDS-10\% polyacrylamide gels and identified by autoradiography.

that the protein becomes associated with an insoluble fraction in the cell. This assumption is, in part, supported by the presence of the capsid protein in the remaining pellet after clarification of the cell extracts (data not shown). However, late in infection, two bands migrating below the capsid protein reacted with anti-capsid antibodies, suggesting that at least some degradation may also occur. The difference in the behavior of this protein may, however, be explained by the fact that it normally binds to the genomic viral RNA.

The p62 and E1 proteins are cleaved from one another by two cotranslational cleavages that release a $6-\mathrm{kDa}$ peptide which is located between the two proteins (39). Signal peptidase has been suggested to be responsible for these two proteolytic events $(20,21,24)$. By immunoblot analysis, a protein reacting with both anti-SV and anti-E1 was identified from Sf9 cells. This protein migrated somewhat faster than that from BHK cells or mature E1 derived from purified virions. However, E1 protein synthesized in the presence of tunicamycin comigrated in the two systems. A similar pattern was obtained when the protein was treated with endo$H$. These data suggest that the nonglycosylated forms of the E1 protein from both systems are very similar and that the migration differences of the corresponding glycosylated forms are due to differences in the oligosaccharide structures. This assumption was confirmed by $\mathrm{N}$-terminal sequencing of the first 10 amino acid residues of purified recombinant $\mathrm{E} 1$ protein. The sequence was identical to that of its authentic counterpart (31), showing that the protein is cleaved correctly and that the difference in migration most probably is due to differences in glycosylation between the two systems. 


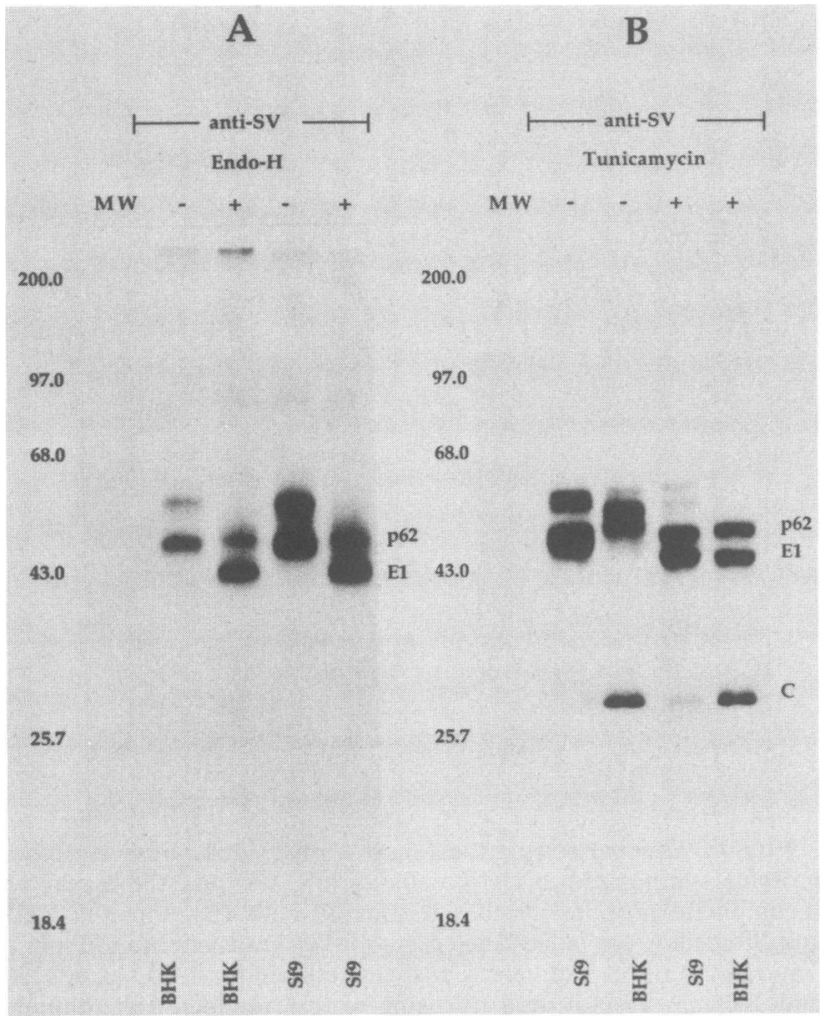

FIG. 6. (A) SDS-gel analysis of immunoprecipitated authentic and recombinant Sindbis virus structural proteins followed by treatment with endo-H. Sindbis virus-infected BHK cells and Sf9 cells infected with the recombinant baculovirus (Ac373-SV26) were labeled with $\left[{ }^{35} S\right]$-Translabel at 3 and 24 h p.i., respectively for 15 min. Cytoplasmic extracts were prepared, and immunoprecipitation was performed by using antibodies to whole virus (anti-SV). The immune complexes were treated with endo- $\mathrm{H}$, and proteins were separated and prepared for autoradiography as described in the text. Molecular weight markers (in thousands) are shown on the left. (B) SDS-gel analysis of immunoprecipitated authentic and recombinan Sindbis virus structural proteins synthesized in the absence and presence of tunicamycin. BHK cells infected with Sindbis virus and Sf9 cells infected with the recombinant baculovirus (Ac373-SV26) were pulse-labeled for $1 \mathrm{~h}$ in the absence and presence of tunicamycin $(2 \mu \mathrm{g} / \mathrm{ml})$. Cell and cytoplasmic extracts were prepared, and immunoprecipitation was performed by using antibodies to whole virus (anti-SV) as described in the text. Molecular weight markers (in thousands) are shown on the left.

The final proteolytic cleavage, i.e., the conversion of p62 to the E2 (and E3) protein, occurs late in trans-Golgi and has been suggested to be mediated by a Golgi protease $(7,19,24$, 39). However, there is some evidence that this cleavage may be virus mediated (M. E. Knipfer and D. T. Brown, submitted for publication). The p62 from Sf9 cells migrates slightly faster than that from BHK cells. The cleavage of this protein to the E2 protein occurs 30 to $60 \mathrm{~min}$ after synthesis as shown by pulse-chase labeling and immunoprecipitation. The E2 protein migrates faster than that obtained from BHK cells and that purified from virions. The slightly higher mobility of recombinant p62 and E2 could, as most probably is the case for $\mathrm{E} 1$, be due to differences in glycosylation. However, the recombinant p62 synthesized in the presence of tunicamycin appears to have a slightly higher mobility than that from BHK cells. This indicates that at least a sequence corresponding to the $6-\mathrm{kDa}$ peptide is released

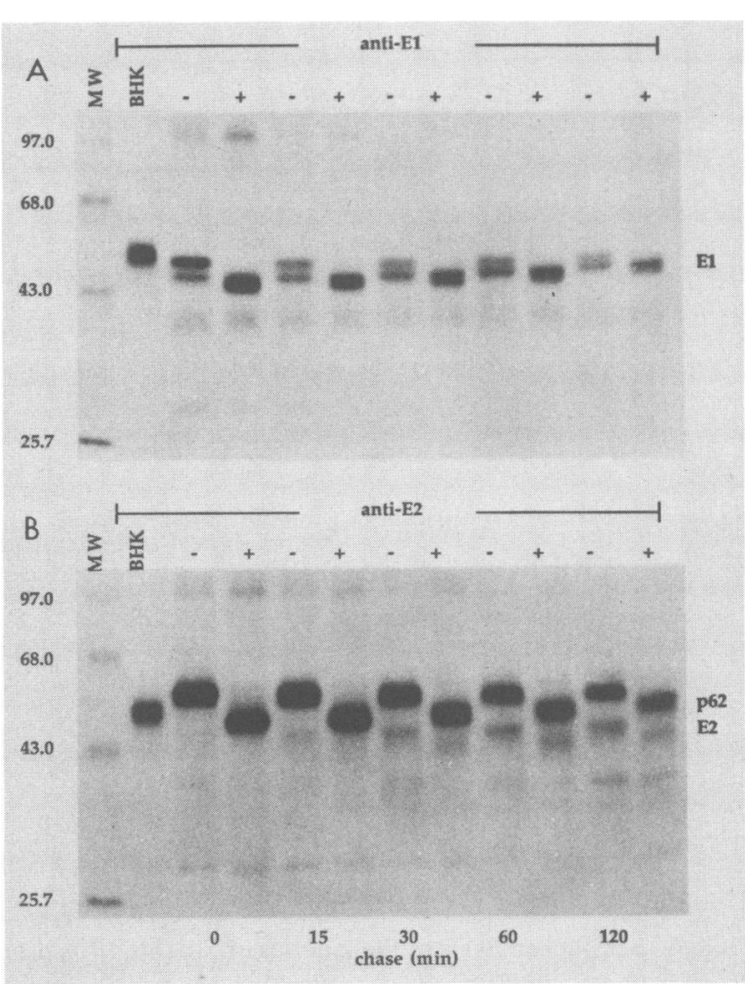

FIG. 7. SDS-gel analysis of immunoprecipitated recombinant Sindbis virus envelope glycoproteins after pulse-chase labeling and treatment with endo-H. Infected Sf9 cells were labeled with $\left[{ }^{35} \mathrm{~S}\right]$ Translabel for $15 \mathrm{~min}$ at $24 \mathrm{~h}$ p.i. and then subjected to a 0 - to 120 -min chase as indicated in the figure. Cell extracts were prepared, and proteins were immunoprecipitated by using anti-E1 antibodies (A) or anti-E2 antibodies (B). At each time point postlabeling, the immune complexes were not treated $(-)$ or treated $(+)$ with endo-H. Untreated E1 and E2 respectively from BHK cells and the molecular weight markers (in thousands) are shown on the left.

from this precursor protein. Since it is believed that signal peptidase is responsible for both the $\mathrm{N}$ - and C-terminal cleavages of the $6-\mathrm{kDa}$ peptide $(20,21,24)$, it is likely that this peptide is cleaved correctly in $\mathrm{Sf} 9$ cells as judged from the N-terminal sequence analysis of $\mathrm{E} 1$. The migration difference of recombinant E1 and E2 is very similar to that of their authentic counterparts. Both of them have two potential N-linked glycosylation sites. This would support a correct cleavage of p62 to E2. In addition, the conversion of p62 has been shown to be a late Golgi event in Sindbis virusinfected vertebrate cells. According to the pulse-chase experiments, the conversion of this protein takes place at about the same time postsynthesis at $28^{\circ} \mathrm{C}$, which further supports the authenticity of this speculation.

According to the results presented above, it is clear that Sf9 cells are capable of expressing and processing the Sindbis virus $26 S$ transcription-translation unit similarly, if not identically, to an authentic Sindbis virus infection, with the exception of differences in oligosaccharide structures. This is fully in agreement with earlier observations on glycosylation in insect cells (reviewed in reference 16). Whether these recombinant proteins are functional remains an unsolved question, since we have not yet been successful in infecting Sf9 cells with Sindbis virus. However, within a broader context, our results support the use of the baculovirus system for the expression of foreign genes and in particular genes encoding polyproteins. 


\section{ACKNOWLEDGMENTS}

We express our sincere thanks to James Strauss and Chang Hahn for providing the $26 \mathrm{~S} \mathrm{cDNA}$ of Sindbis virus and for antisera directed against the individual structural proteins. We also thank Sondra and Milton Schlesinger for providing Sindbis virus and BHK cells and for helpful discussions. We are grateful to Dennis Brown for providing antiserum to whole Sindbis virus and for helpful advice. Thanks are also due to Hans Nitschko for purified Sindbis virus glycoproteins; to Timothy Hayes and Martha Miller, TAES Biotechnology Support Laboratory, for the protein sequence analysis; and Nancy LeGendre for good advice concerning quantitative isolation of proteins.

This study was funded in part by a grant from the Kleberg Foundation and by Texas Agricultural Experiment Station, project 6316.

\section{LITERATURE CITED}

1. Aliperti, G., and M. J. Schlesinger. 1978. Evidence for an autoprotease activity of Sindbis virus capsid protein. Virology 90:366-369.

2. Bonatti, S., R. Cancedda, and G. Blobel. 1979. Membrane biogenesis: in vitro cleavage, core glycosylation and integration into microsomal membranes of Sindbis virus glycoproteins. J. Cell Biol. 80:219-224.

3. Brown, D. T., and L. D. Condreay. 1986. Replication of alphaviruses in mosquito cells, p. 171-207. In S. Schlesinger and M. J. Schlesinger (ed.), The Togaviridae and Flaviviridae. Plenum Publishing Corp., New York.

4. Cancedda, R., R. Swanson, and M. J. Schlesinger. 1974. Viral proteins formed in a cell-free rabbit reticulocyte system programmed with RNA from a temperature-sensitive mutant of Sindbis virus. J. Virol. 14:664-671.

5. Clegg, J. C. S., and S. I. T. Kennedy. 1974. In vitro synthesis of structural proteins of Semliki Forest virus directed by isolated 26S RNA from infected cells. FEBS Lett. 42:327-330.

6. Clegg, J. C. S., and S. I. T. Kennedy. 1975. Translation of Semliki Forest virus intracellular 26S RNA; characterization of the products synthesized in vitro. Eur. J. Biochem. 53:175184.

7. Garoff, H., A.-M. Frischauf, K. Simons, H. Lehrach, and H. Delius. 1980. Nucleotide sequence of cDNA coding for Semliki Forest virus membrane glycoproteins. Nature (London) 288: 236-241.

8. Garoff, H., C. Kondor-Koch, and H. Riedel. 1982. Structure and assembly of alphaviruses. Curr. Top. Microbiol. Immunol. 99:1-50.

9. Garoff, H., K. Simons, and B. Dobberstein. 1978. Assembly of the Semliki Forest virus membrane glycoproteins in the membrane of the endoplasmatic reticulum in vitro. J. Mol. Biol. 124:587-600.

10. Glanville, N., J. Morser, P. Uomala, and L. Kääriäinen. 1976. Simultaneous translation of structural and nonstructural proteins from Semliki Forest virus RNA in two eukaryotic systems in vitro. Eur. J. Biochem. 64:167-175.

11. Hahn, C. S., E. G. Strauss, and J. H. Strauss. 1985. Sequence analysis of three Sindbis virus mutants temperature-sensitive in the capsid protein autoprotease. Proc. Natl. Acad. Sci. USA 82:4648-4652.

12. Hsieh, P., and P. W. Robbins. 1984. Regulation of asparaginelinked oligosaccharide processing. Oligosaccharide processing in Aedes albopictus mosquito cells. J. Biol. Chem. 259:23752382.

13. Hunkapiller, M. W., R. M. Hewick, W. J. Dreyer, and L. E. Hood. 1983. High-sensitivity sequencing with a gas-phase sequenator. Methods Enzymol. 91:399-413.

14. Huth, A., T. A. Rapoport, and L. Kääriäinen. 1984. Envelope proteins of Semliki Forest virus synthesized in Xenopus oocytes are transported to the cell surface. EMBO J. 3:767-771.

15. Laemmli, U. K. 1970. Cleavage of structural proteins during the assembly of the head of bacteriophage T4. Nature (London) 227:680-685.
16. Luckow, V. A., and M. D. Summers. 1988. Trends in the development of baculovirus expression vectors. Bio/Technology 6:47-55.

17. Maniatis, T., E. F. Fritsch, and J. Sambrook. 1982. Molecular cloning: a laboratory manual. Cold Spring Harbor Laboratory, Cold Spring Harbor, N.Y.

18. Mann, E., J. Edwards, and D. T. Brown. 1983. Polycaryocyte formation mediated by Sindbis glycoproteins. J. Virol. 45: 1083-1089.

19. Mayne, J. T., C. M. Rice, E. G. Strauss, M. W. Hunkapiller, and J. H. Strauss. 1984. Biochemical studies on the maturation of the small Sindbis virus glycoprotein E3. Virology 134:338357.

20. Melancon, P., and H. Garoff. 1986. Reinitiation of translocation in the Semliki Forest virus structural polyprotein: identification of the signal for the E1 glycoprotein. EMBO J. 7:15431550 .

21. Melancon, P., and H. Garoff. 1987. Processing of Semliki Forest virus structural polyprotein: role of the capsid protease. J. Virol. 61:1301-1309.

22. Oker-Blom, C., N. Kalkkinen, L. Kääriäinen, and R. F. Pettersson. 1983. Rubella virus contains one capsid protein and three envelope glycoproteins, E1, E2a, and E2b. J. Virol. 46:964973.

23. Rice, C. M., C. A. Franke, J. H. Strauss, and D. H. Hruby. 1985. Expression of Sindbis virus structural proteins via recombinant vaccinia virus: synthesis, processing, and incorporation into mature Sindbis virions. J. Virol. 56:227-239.

24. Rice, C. M., and J. H. Strauss. 1981. Nucleotide sequence of the $26 \mathrm{~S}$ mRNA of Sindbis virus and deduced sequence of the encoded viral structural proteins. Proc. Natl. Acad. Sci. USA 78:2062-2066.

25. Scheefers, H., V. Scheefers-Borchel, J. Edwards, and D. T. Brown. 1980. Distribution of virus structural proteins and protein-protein interactions in plasmid membrane of baby hamster kidney cells infected with Sindbis or vesicular stomatitis virus. Proc. Natl. Acad. Sci. USA 77:7277-7281.

26. Schlesinger, M. J. 1987. The replication of Togaviridae and Flaviviridae at the molecular level, p. 217-237. In R. P. Bercoff (ed.), The molecular basis of viral replication. Plenum Publishing Corp., New York.

27. Schlesinger, M. J., and L. Kääriäinen. 1980. Translation and processing of alphavirus proteins, p. 371-392. In R. W. Schlesinger (ed.), The togaviruses. Academic Press, Inc., New York.

28. Schlesinger, M. J., and S. Schlesinger. 1986. Formation and assembly of alphavirus glycoproteins, p. 121-148. In S. Schlesinger and M. J. Schlesinger (ed.), The Togaviridae and Flaviviridae. Plenum Publishing Corp., New York.

29. Scupham, R. K., K. J. Jones, B. P. Sagik, and H. R. Bose, Jr. 1977. Virus-directed post-translational cleavage in Sindbis virus infected cells. J. Virol. 22:568-571.

30. Simmons, D. T., and J. H. Strauss. 1974. Translation of Sindbis virus 26S RNA and 49S RNA in lysates of rabbit reticulaocytes. J. Mol. Biol. 86:397-409.

31. Strauss, E. G., C. M. Rice, and J. H. Strauss. 1984. Complete nucleotide sequence of the genomic RNA of Sindbis virus. Virology 133:92-110.

32. Strauss, E. G., and J. H. Strauss. 1983. Replication strategies of single stranded RNA viruses of eukaryotes. Curr. Top. Microbiol. Immunol. 105:1-98.

33. Strauss, E. G., and J. H. Strauss. 1986. Structure and replication of the alphavirus genome, p. 35-90. In S. Schlesinger and M. J. Schlesinger (ed.), The Togaviridae and Flaviviridae. Plenum Publishing Corp., New York.

34. Summers, M. D., and G. E. Smith. 1987. A manual of methods for baculovirus vectors and insect cell culture procedures. Texas Agricultural Experiment Station Bulletin no. 1555. Texas Agricultural Experiment Station, Texas A\&M University, College Station, Tex.

35. Takatsuki, A., K. Kohno, and G. Tamura. 1975. Inhibition of biosynthesis of polyisoprenol sugars in chick embryo microsomes by tunicamycin. Agric. Biol. Chem. 39:2089-2091. 
36. Tarentino, A. L., and F. Maley. 1974. Purification and properties of an endo- $\beta-\mathrm{N}$-acetylglucosaminidase from Streptomyces griseus. J. Biol. Chem. 249:811-817.

37. Tkacz, J. S., and O. Lampen. 1975. Tunicamycin inhibition of polyisoprenol $\mathrm{N}$-acetylglucosaminyl pyrophosphate formation in calf liver microsomes. Biochem. Biophys. Res. Commun. 65:248-257.
38. Towbin, H., T. Staehelin, and J. Gordon. 1979. Electrophoretic transfer of proteins from polyacrylamide gels to nitrocellulose sheets: procedure and some applications. Proc. Natl. Acad. Sci. USA 76:4350-4354.

39. Welch, W. J., and B. M. Sefton. 1979. Two small virus-specific polypeptides are produced during infection with Sindbis virus. J. Virol. 29:1186-1195. 